\title{
A Grey MCDM Based on DEMATEL Model for Real Estate Evaluation and Selection Problems: A Numerical Example
}

\author{
Phi-Hung NGUYEN ${ }^{1}$, Jung-Fa TSAI ${ }^{2}$, Thanh-Tam NGUYEN ${ }^{3}$, Thi-Giang NGUYEN ${ }^{4}$, Dang-Duong VU ${ }^{5}$ \\ Received: August 01, 2020 Revised: September 20, 2020 Accepted: October 05, 2020
}

\begin{abstract}
Real estate markets play an essential role in the economic development of both developed and developing countries. Investment decisions in private real estate demand the consideration of several qualitative and quantitative criteria. Especially in Vietnam, demand for housing, apartments are rising which has resulted because of the migration from rural to urban areas. This study aims to determine the influencing factors of the real estate purchasing behavior and then recommend a grey Multi-Criteria Decision Making (MCDM) support model to evaluate real estate alternatives based on a numerical example in Vietnam. A set of essential criteria are identified based on experts' opinion, and the proposed determinants are initial investment, maintenance cost, prestige location, distance to interesting places, parking lot, public transportation, property condition, total area size, number of rooms, and neighbors. The subjective weights were obtained by using the Decision-Making Trial and Evaluation Laboratory (DEMATEL) model, and the Grey Relational Analysis (GRA) technique is employed to prioritize and rank real estate alternatives. The results reveal that this approach can be useful to make purchasing decisions for many kinds of real estate property under uncertain business environments. These findings indicate that the presented hybrid model has advantages in granting flexibility to the preferences of decision makers.
\end{abstract}

Keywords: Evaluation and Selection, MCDM, DEMATEL, GRA, Real Estate

JEL Classification Code: C02, C61, D53, Q14

\section{Introduction}

The real estate market is closely related with economic and social development. The performance of the real estate market is a reflection of a country's macroeconomic

${ }^{1}$ First Author and Corresponding Author. [1] PhD Researcher, SAB Lab, Faculty of Business, FPT University, Hanoi, Vietnam [Postal Address: Hoa Lac High-Tech Park, Km 29, Thang Long Boulevard, Hanoi, 100000, Vietnam] Email: hungnp30@fe.edu.vn [2] Department of Business Management, National Taipei University of Technology, Taipei, Taiwan. Email: hungnp30@fe.edu.vn

${ }^{2}$ Department of Business Management, National Taipei University of Technology, Taipei, Taiwan. Email: jftsai@ntut.edu.tw

${ }^{3}$ Faculty of Business, FPT University, Hanoi, Vietnam.

Email: tamnt17@fe.edu.vn

${ }^{4}$ Faculty of Business, FPT University, Hanoi, Vietnam.

Email: giangnths140548@fpt.edu.vn

${ }^{5}$ Faculty of Business, FPT University, Hanoi, Vietnam.

Email: duongvdhs130259@fpt.edu.vn

() Copyright: The Author(s)

This is an Open Access article distributed under the terms of the Creative Commons Attribution Non-Commercial License (https://creativecommons.org/licenses/by-nc/4.0/) which permits unrestricted non-commercial use, distribution, and reproduction in any medium, provided the original work is properly cited. development and economic growth. However, the real estate market is also a sub-sector of the economy which drives economic growth by directly interacting with the construction industry and the financial sector. In many countries, the wealth effect generated by the increase in housing prices, which can even lead to equity withdrawal, has a strong effect on consumption (Apergis et al. 2019; Geipele \& Kauškale, 2013; Wang et al. 2011; Zhang, 2015).

Miller et al. (2011) argued that the housing market, representing the real estate market, plays an important role in the economy. This is evident when the housing market rescued the US economy from a severe downturn when the US stock market plunged in 2001, or the fact that the housing market crisis led to global economic downturn in 2008. There is a free flow of information available to both buyers and sellers of commodities, the price-setting mechanism rests on the forces of demand and supply. On the one hand there are demand considerations based on marginal utility, while on the other hand there are supply considerations based on the marginal cost in a liberalized market (Hott, 2011; Jovanovic, 2008; Kibunyi et al. 2017). 
Bouchouicha and Ftiti (2012) examined the dynamic interactions between real estate markets, in the US and the UK and their macroeconomic environments. Their results showed that wealth and housing expenditure channels are very conductive during real estate crises in the US. However, only the wealth effect is significant as a transmission channel during real estate market downturns in the US. Brzezicka et al. (2019) also analyzed the spread of market phenomena, market tensions, and trends between real estate markets on a global scale. Their study aimed to determine the strength of the correlations between the real estate markets of the world's ten largest countries with the highest GDP. Their results revealed strong correlations between most of the markets; however, we did not find strong evidence for causality. In a globalizing world, national economies will become increasingly interconnected, which will indirectly influence the housing market.

Recently, Nguyen et al. (2019) stated that the real estate market positively impacts Vietnam's economic growth. It is a fact that the real estate market in Vietnam is still new, so there are many limitations in the researching process. They also found that both real estate market and economic growth fluctuated and are affected by the past shocks of the selected factors. In recent years, Vietnam's economy has experienced many difficult stages; the demand for real estate in large cities has increased, which has made the real estate market, as well as the economy, consistently unpredictable and risky (Ministry of Construction of Vietnam, 2016). Besides, the real estate market in Vietnam experienced a difficult period and a significant decline in 2012. During this period, the volume of housing transactions fell sharply, the real estate sector had difficulty accessing capital due to the policy of tightening bank credit, and Vietnam's economy still declined in 2012 (TCER, 2014).

Jung et al. (2013) compared the investment strategies by foreign and local developers in the residential market in Vietnam. They found that domestic investors were active primarily in central areas while foreign investors chose to invest mainly in suburban areas. Foreign investors apparently cluster together and create new values for areas with poor conditions, while with their social network and understanding of the local market, local investors have better opportunities to acquire land in central areas, or already own lands in the city centre.

Besides, Nguyen et al. (2020) studies are based on the viewpoints of people with real housing needs in order to investigate the determining factors affecting apartment prices in Ho Chi Minh City with the Hedonic method to establish a scientific foundation for more accurate pricing in the real estate market. The research results revealed that five significant factors which positively affect the price of apartments in Ho Chi Minh City are - apartment area, toilet and bedroom, apartment floor, reference price, and apartment interior.
The real estate in Vietnam has got specific characteristics to which connected customer demands closely. In recent years, researchers, domestic and foreign companies attracted to real estate field in Vietnam with a number of research works. However, there is a lack of research on the real estate purchasing intention and major factors influencing customer decision. Understanding the relationship between main factors affecting customer house purchase decision is a vital role for both real estate developers and enterprises to satisfy customers' demand and to have available strategies in the real estate field (Si, 2012).

Furthermore, real estate purchasing decision is also considered as a multi-criteria decision making in real life. The decision making in the real estate area is now more complicated and consists of many decision alternatives, in order to pick up the one that fits best with the goal, desires, and values of the decision-makers. Related to the topic of this research, Tang \& Jin (2020) also introduced the method of grey absolute relational analysis to construct the grey relational degree model of house price influencing factors and quantitatively calculate the grey correlation between each index and house price using the data of Nanjing City from 2006 to 2015 (Tang \& Jin, 2020).

Multi-criteria decision making (MCDM) methods, referring to screening, prioritizing, ranking, or selecting a set of alternatives which are usually under independent, incommensurate or conflicting attributes, are the most active research areas in the literature and have been applied in a wide range of decision areas. (Aldalou \& Percin, 2020; Brauers \& Zavadskas, 2006; Fasanghari \& Montazer, 2010; Giannakis et al. 2020; Ishtiaq \& Siddiqui, 2019; Nguyen et al. 2020; Singhal, Tripathy et al. 2018; Škrinjarić, 2020; Yalcin et al. 2012; Ying-Yu \& De-Jian, 2011, ). Although many researchers use MCDM methods in other fields, there are only few researchers who use MCDM methods in real estate purchasing behaviors. This study proposes a hybrid method of GRA and DEMATEL to assist real estate purchasing selection. The DEMATEL methods will be used to identify the criteria weights and GRA will be used to ranking real estate alternatives.

After the introduction section, this study is organized as follows: Section 2 briefly explained the selected criteria to avoid repeated with alternative researches. In section 3, MCDM approaches of DEMATEL, GRA are summarized. An empirical example is discussed. The final section concluding our findings and insights for future studies are clarified.

\section{Proposed Criteria}

Five experts working as real-estate researchers, manager, investors and traders were interviewed in Hanoi, Vietnam; the experts are experienced with high-end apartments. The results showed that experts identified that ten factors are appropriate and did not add any more factors (Table 1). 
Table 1: Criteria

\begin{tabular}{|l|l|}
\hline M1 & Initial investment \\
\hline M2 & Maintenance running cost \\
\hline M3 & Prestige location \\
\hline M4 & $\begin{array}{l}\text { Distance to interesting places (hospital, } \\
\text { supermarket, school. etc.) }\end{array}$ \\
\hline M5 & Parking lot \\
\hline M6 & Public transportation \\
\hline M7 & Property condition \\
\hline M8 & Total area ( m2) size \\
\hline M9 & No of Rooms \\
\hline M10 & Neighbourhood \\
\hline
\end{tabular}

\subsection{Initial Investment}

Initial investment is the amount of money required to start a business or buying a real estate property.

\subsection{Maintenance Running Cost}

The maintenance running costs are defined as the total cost of operating and maintenance costs.

\subsection{Prestige Location}

The location of real estate is one of the main factors affecting property prices. For example, the surrounding air quality influences the value of the apartments, or a near-by water treatment plant will result in a decrease in the value of the apartments. The prestigious location, for example, an apartment with a unique view landscape outside, dramatically impacts the satisfaction and love of the accommodation. It also adds many values in order to make the decision to buy that apartment easier.

\subsection{Distance to Interesting Places (Hospital, Supermarket, School):}

Distance to exciting places like shopping malls, schools, and hospitals also have an essential effect on the real estate price. The best case is the most convenient distance for different types of transportation to these places mentioned above, along with the lowest and most economical traveling costs. The distance of the apartment is expected to be inversely proportional to the apartment's price.

\subsection{Parking Lot}

The availability of parking lot can influence how much a person is willing to pay for the real estate. In most bustling cities, parking is a rare commodity. While many city dwellers expect parking spaces to be scarce, the availability of parking spaces can significantly affect the price they are willing to pay. For example, homes with off-street parking available will likely have more value; therefore, higher prices. The fewer parking spots available, the buyers are willing to pay. Otherwise, real estate in suburban areas is expected to have off-street parking, such as driveways and garages, to be included in the purchase. Because of this factor, homes with only street parking options are required to be discounted in order to sell in a reasonable amount of time.

\subsection{Public Transportation}

Transport plays a crucial role in the urban development process by providing more efficient access to education, markets, employment, recreation, health care, and many other critical services to the citizens. Although a house located near public transports will tend to have higher prices due to the quick and convenience in transporting, some studies have found that this can also bring adverse effects on property values.

\subsection{Property Condition}

Clients are always seeking to know the condition of a property or real estate they may be purchasing, leasing, financing or simply maintaining. Buyers can save their money by checking some of the critical parts of the house like plumbing, electrical set-ups, the roof, and the appliances to see whether or not they are new and they are not likely to break down. In conclusion, the better the condition of the property is, the higher its value is.

\subsection{Total Area (m2) Size}

The total area which it is owned can be the first factor that comes to mind in determining the value of a real estate. The value of a property is roughly estimated by the price per square foot.

\subsection{Number of Rooms}

The number of rooms is another important factor affecting the buyer's decision. Having more rooms means more usable space, therefore, a higher value. For instance, bedrooms and bathrooms are most highly valued in most of the cases.

\subsection{Neighborhood}

Neighborhood should be taken into consideration when choosing a house as it has a significant effect on its future value. A house may look great and meet all the requirements 
from the buyer, but if there are neighbors that are bothering or disturbing in many ways, will lead to a decrease in the value of the property. For example, some neighborhood's factors which are affecting the property value are local crime, unpleasant odors, annoying pets, foreclosure, poorly maintained exteriors, and many more.

\section{Methodology}

Multi-criteria decision making (MCDM) is the process of finding the best alternatives from all of the feasible alternatives where all the alternatives can be evaluated according to a number of criteria or attributes. This study proposed a hybrid method of DEMATEL and GRA. DEMATEL method is employed to identify the weights of critical real estate purchasing criteria based on the experts' opinion. The GRA technique is used to evaluate and rank the real estate options. The evaluation procedure in this paper consists of three main steps as follows:

Step 1. Identify the evaluation criteria considered as the most important factors for real estate purchasing criteria.

Step 2. Construct the hierarchy of the evaluation criteria and calculate the weights of these criteria using DEMATEL method.

Step 3. Conduct the GRA methods to achieve the final ranking results.

\subsection{DEMATEL}

Decision making trial and evaluation laboratory (DEMATEL) technique was first developed by the Geneva Research Centre of the Battelle Memorial Institute to visualize the structure of complicated causal relationships through matrices or digraphs. As a kind of structural modeling approach, it is especially useful in analyzing the cause and effect relationships among components of a system. The DEMATEL can confirm interdependence among factors and aid in the development of a map to reflect relative relation- ships within them and can be used for investigating and solving complicated and intertwined problems (Gabus \& Fontela, 1972) .

Step 1: $K$ direct-relation matrices $\left(Z^{1}, Z^{2}, . ., Z^{k}\right)$ of each expert are obtained. Then the average direct-relation matrix is taken by Eq. (1)

$$
\mathrm{Z}=\sum_{i=1}^{k} Z^{k} / \mathrm{k}
$$

Step 2: The normalized matrix A is obtained by Eq. (2) and (3)

$$
\begin{gathered}
\mathrm{K}=1 / \max \sum_{j=1}^{n} a^{i j} \\
\mathrm{X}=\mathrm{K} \times \mathrm{A}
\end{gathered}
$$

Step 3: Computing the sum of rows $\left(\mathrm{D}_{\mathrm{i}}\right)$ and the sum of columns $\left(\mathrm{R}_{\mathrm{i}}\right)$ by Eq. (4) and (5), respectively:

$$
\begin{aligned}
& D=\left[\sum_{j=1}^{n} \boldsymbol{m}_{i j}\right] n \times l \\
& R=\left[\sum_{i=1}^{n} \boldsymbol{m}_{i j}\right] l \times n
\end{aligned}
$$

Step 4: Creating the value of $\left(\mathrm{R}_{\mathrm{i}}+\mathrm{D}_{\mathrm{i}}\right),\left(\mathrm{R}_{\mathrm{i}}-\mathrm{D}_{\mathrm{i}}\right)$. The influencing factors can then be shown in the causal relationship diagram.

Step 5: Determining criteria weights using the results of DEMATEL with Eq. (6), (7) in this study.

$$
\begin{aligned}
& \mathrm{W}_{\mathrm{i}}=\left[\left(\mathrm{R}_{\mathrm{i}}+\mathrm{D}_{\mathrm{i}}\right)^{2}+\left(\mathrm{R}_{\mathrm{i}}-\mathrm{D}_{\mathrm{i}}\right)^{2}\right]^{1 / 2} \\
& \mathrm{~W}_{\mathrm{i}}^{\text {nor }}=\mathrm{W}_{\mathrm{i}} / \sum_{i=1}^{n} W_{i}
\end{aligned}
$$

Where $\mathrm{W}_{\mathrm{i}}^{\text {nor }}$ is normalized weights of criteria.

\subsection{GRA}

Grey system theory was introduced by (Deng J, 1989). GRA is a technique of grey theory for analyzing the relationship between a reference series and other series. It consists of three steps normalization of the decision matrix, estimation of grey relational coefficient followed by estimation of grey relational grade (GRG) eventually ranking the best alternative based on the highest value of GRG.

Step 1: The normalization of the decision matrix using Eq. (8) \& Eq. (9)

For lower-the-better attributes

$$
Z_{i j}=\frac{z_{i j}^{\max }-z_{i j}}{z_{j}^{\max }-z_{j}^{\min }}
$$

For higher-the-better attributes

$$
Z_{i j}=\frac{z_{i j}-z_{i j}^{\min }}{z_{j}^{\max }-z_{j}^{\min }}
$$

Step 2: Obtaining the grey relational coefficient (GRC), which shows the relationship between ideal and normalized data, estimated by using Eq. (10)

$$
\xi_{i}(k)=\frac{\Delta_{\min }+\zeta \Delta_{\max }}{\Delta_{\dot{b}}(k)+\zeta \Delta_{\max }}
$$


Where $\Delta_{\dot{\theta}}(k)=\left\|Z_{0}^{*}(k)-Z_{i}^{*}(k)\right\|, Z_{0}^{*}(k)$ represents the reference sequence and $Z_{i}^{*}(k)$ represents the comparability sequence. $\Delta_{\min }$ and $\Delta_{\max }$ are the minimum and maximum values if. $\Delta_{\dot{\phi}}(k)$. The distinguished coefficient $\zeta$ varied from 0 to 1 , here for the solving $\zeta$ considered as 0.5 .

Step 3: Grey relational Grade (GRG) is estimated by averaging the GRC with weights for all the attributes by using Eq. (11).

$$
\gamma_{i}=\frac{1}{n} \sum_{k=1}^{n} \omega_{k} \xi_{i}(k)
$$

Where $\omega_{k}$ represents the subjective weights of proposed criteria, calculated by the DEMATEL method. Consequently, the residential property alternatives can be ranked according to GRG. The higher GRG shows a better choice.

\section{Empirical Results and Discussion}

\subsection{Criteria Weighting by DEMATEL}

This study uses 10 evaluation criteria and symbols as follows: (M1) Initial investment; (M2) Maintenance (running cost); (M3) Prestigious location; (M4) Distance to interesting places; (M5) Parking lot; (M6) Public transportation; (M7) Property condition; (M8) Total area size; (M9) No of Rooms; (M10) Neighbourhood. The DEMATEL method is also used to evaluate the influence of each criterion in real estate selection. This research first designed a questionnaire for DEMATEL composed of three parts. The first part outlines each criterion definition for easy understanding and response. Then, respondents were asked to compare the importance of each criterion using scores $1,2,3$, and 4 to represent the degree of significance. Scores of 1, 2, 3, and 4 to represent "no importance", "low importance", "high importance", and "very high importance", respectively. The second part is a pair-wise comparison to evaluate the influence of each score, where scores of $0,1,2,3$ and 4 represent "no influence", "low influence", "normal influence", "high influence", and "very high influence", respectively. The final part is the analyzed data. The study obtains the average value of initial direct-relation matrixes from the total amount of all initial direct-relation matrixes divided by 5 (the number of experts) in Table 2. The determination of subjective weights for the corresponding attributes were obtained and shown in Table 3 .

The results of criteria weights also presented the rank of each criterion of real estate purchasing behavior in order to consider the realistic and complex nature of the decision analysis and to reach a quality decision that will include every essential factor. The most critical factor is (M1) Initial investment outlay, and the following orders are (M3) Prestigious location and (M8) Total area size. (M5) Parking lot; (M6) Public transportation and (M10) Neighbourhood are not significant factors influencing real estate evaluation and selection. $(\mathrm{M} 1>\mathrm{M} 3>\mathrm{M} 8>\mathrm{M} 4>\mathrm{M} 7>\mathrm{M} 2>\mathrm{M} 9>\mathrm{M} 6>\mathrm{M} 5>\mathrm{M} 10)$.

\subsection{GRA Based on DEMATEL Weights}

For the ranking of the real estate alternatives, the GRA method is employed first. The decision matrix is given in Table 4 is normalized based on the lower-the-better and higher-the-better using the Eq. (8) \& Eq. (9) the normalized values are represented in Table 5. Further, the weights obtained from DEMATEL used for evaluating the grey relational grade using the Eq. (10), based on the grade values, the ranking of the empirical real estate options by GRA is $\mathrm{A} 4>\mathrm{A} 10>\mathrm{A} 9>\mathrm{A} 2>\mathrm{A} 5>\mathrm{A} 7>\mathrm{A} 3>\mathrm{A} 6>\mathrm{A} 1>\mathrm{A} 9$ (Table 6).

Table 2: Average Matrix

\begin{tabular}{|l|c|c|c|c|c|c|c|c|c|c|}
\hline & M1 & M2 & M3 & M4 & M5 & M6 & M7 & M8 & M9 & M10 \\
\hline M1 & 0 & 3 & 4 & 3 & 1 & 2 & 3 & 4 & 3 & 3 \\
\hline M2 & 2 & 0 & 2 & 3 & 1 & 2 & 2 & 3 & 1 & 1 \\
\hline M3 & 3 & 2 & 0 & 4 & 3 & 3 & 2 & 4 & 2 & 1 \\
\hline M4 & 3 & 3 & 3 & 0 & 3 & 2 & 2 & 2 & 2 & 1 \\
\hline M5 & 2 & 1 & 2 & 2 & 0 & 1 & 2 & 1 & 1 & 1 \\
\hline M6 & 1 & 1 & 3 & 2 & 2 & 0 & 1 & 2 & 1 & 1 \\
\hline M7 & 3 & 3 & 3 & 1 & 1 & 1 & 0 & 2 & 2 & 1 \\
\hline M8 & 3 & 2 & 3 & 3 & 2 & 1 & 3 & 0 & 4 & 1 \\
\hline M9 & 2 & 2 & 1 & 1 & 1 & 1 & 2 & 3 & 0 & 1 \\
\hline M10 & 1 & 1 & 2 & 2 & 1 & 2 & 1 & 1 & 1 & 0 \\
\hline
\end{tabular}


Table 3: DEMATEL Results and Criteria Weights

\begin{tabular}{|l|c|c|c|c|c|c|}
\hline Criteria & $\mathbf{D i}$ & $\mathbf{R i}$ & $\mathbf{D i + R i}$ & $\mathbf{D i - R i}$ & $\mathbf{W}$ & $\mathbf{W}$ \\
\hline M1 & 3.487 & 2.770 & 6.257 & 0.717 & 6.298 & 0.127 \\
\hline M2 & 2.395 & 2.504 & 4.900 & -0.109 & 4.901 & 0.098 \\
\hline M3 & 3.251 & 3.081 & 6.333 & 0.170 & 6.335 & 0.126 \\
\hline M4 & 2.857 & 2.866 & 5.723 & -0.009 & 5.723 & 0.115 \\
\hline M5 & 1.846 & 2.105 & 3.951 & -0.258 & 3.959 & 0.080 \\
\hline M6 & 1.965 & 2.062 & 4.027 & -0.097 & 4.028 & 0.081 \\
\hline M7 & 2.410 & 2.496 & 4.906 & -0.086 & 4.907 & 0.099 \\
\hline M8 & 3.000 & 3.024 & 6.024 & -0.024 & 6.024 & 0.121 \\
\hline M9 & 1.968 & 2.404 & 4.372 & -0.436 & 4.393 & 0.088 \\
\hline M10 & 1.664 & 1.533 & 3.196 & 0.131 & 3.199 & 0.064 \\
\hline
\end{tabular}

Table 4: Decision Matrix

\begin{tabular}{|l|c|c|c|c|c|c|c|c|c|c|}
\hline & M1 & M2 & M3 & M4 & M5 & M6 & M7 & M8 & M9 & M10 \\
\hline ALT1 & 50 & 500 & 6 & 2 & 5 & 3 & 2 & 80 & 2 & 1 \\
\hline ALT2 & 53 & 530 & 5 & 1.5 & 4 & 3 & 1 & 90 & 1 & 1 \\
\hline ALT3 & 75 & 750 & 7 & 3 & 5 & 3 & 1 & 55 & 2 & 3 \\
\hline ALT4 & 38 & 380 & 7 & 0.5 & 4 & 2 & 0 & 68 & 1 & 1 \\
\hline ALT5 & 46 & 368 & 5 & 2 & 2 & 2 & 2 & 53 & 2 & 2 \\
\hline ALT6 & 80 & 4000 & 8 & 0.3 & 5 & 3 & 2 & 60 & 1 & 3 \\
\hline ALT7 & 70 & 2100 & 9 & 1 & 5 & 2 & 1 & 65 & 1 & 3 \\
\hline ALT8 & 57 & 1140 & 8 & 2 & 4 & 1 & 2 & 75 & 2 & 3 \\
\hline ALT9 & 52 & 260 & 7 & 3 & 2 & 1 & 0 & 80 & 1 & 2 \\
\hline ALT10 & 51 & 357 & 6 & 2 & 3 & 2 & 1 & 70 & 1 & 1 \\
\hline
\end{tabular}

Table 5: Normalized values for indicators

\begin{tabular}{|l|c|c|c|c|c|c|c|c|c|c|}
\hline & M1 & M2 & M3 & M4 & M5 & M6 & M7 & M8 & M9 & M10 \\
\hline ALT1 & 0.978 & 0.976 & 0.984 & 0.900 & 0.919 & 0.905 & 0.923 & 0.958 & 0.923 & 1.000 \\
\hline ALT2 & 0.972 & 0.973 & 1.000 & 0.929 & 0.946 & 0.905 & 1.000 & 0.942 & 1.000 & 1.000 \\
\hline ALT3 & 0.931 & 0.952 & 0.968 & 0.841 & 0.919 & 0.905 & 1.000 & 0.997 & 0.923 & 0.895 \\
\hline ALT4 & 1.000 & 0.988 & 0.968 & 0.988 & 0.946 & 0.952 & 1.000 & 0.977 & 1.000 & 1.000 \\
\hline ALT5 & 0.985 & 0.989 & 1.000 & 0.900 & 1.000 & 0.952 & 0.923 & 1.000 & 0.923 & 0.947 \\
\hline ALT6 & 0.921 & 0.631 & 0.952 & 1.000 & 0.919 & 0.905 & 0.923 & 0.989 & 1.000 & 0.895 \\
\hline ALT7 & 0.940 & 0.818 & 0.937 & 0.959 & 0.919 & 0.952 & 1.000 & 0.981 & 1.000 & 0.895 \\
\hline ALT8 & 0.964 & 0.913 & 0.952 & 0.900 & 0.946 & 1.000 & 0.923 & 0.966 & 0.923 & 0.895 \\
\hline ALT9 & 0.974 & 1.000 & 0.968 & 0.841 & 1.000 & 1.000 & 1.000 & 0.958 & 1.000 & 0.947 \\
\hline ALT10 & 0.976 & 0.990 & 0.984 & 0.900 & 0.973 & 0.952 & 1.000 & 0.974 & 1.000 & 1.000 \\
\hline
\end{tabular}


Table 6: Grey Relational Coefficient

\begin{tabular}{|l|c|c|c|c|c|c|c|c|c|c|c|c|}
\hline & M1 & M2 & M3 & M4 & M5 & M6 & M7 & M8 & M9 & M10 & Grade & Rank \\
\hline ALT1 & 0.64 & 0.89 & 0.67 & 0.44 & 0.33 & 0.33 & 0.33 & 0.41 & 0.33 & 1.00 & 0.452 & 9 \\
\hline ALT2 & 0.58 & 0.87 & 1.00 & 0.53 & 0.43 & 0.33 & 1.00 & 0.33 & 1.00 & 1.00 & 0.626 & 4 \\
\hline ALT3 & 0.36 & 0.79 & 0.50 & 0.33 & 0.33 & 0.33 & 1.00 & 0.90 & 0.33 & 0.33 & 0.492 & 7 \\
\hline ALT4 & 1.00 & 0.94 & 0.50 & 0.87 & 0.43 & 0.50 & 1.00 & 0.55 & 1.00 & 1.00 & 0.648 & 1 \\
\hline ALT5 & 0.72 & 0.95 & 1.00 & 0.44 & 1.00 & 0.50 & 0.33 & 1.00 & 0.33 & 0.50 & 0.606 & 5 \\
\hline ALT6 & 0.33 & 0.33 & 0.40 & 1.00 & 0.33 & 0.33 & 0.33 & 0.73 & 1.00 & 0.33 & 0.482 & 8 \\
\hline ALT7 & 0.40 & 0.50 & 0.33 & 0.66 & 0.33 & 0.50 & 1.00 & 0.61 & 1.00 & 0.33 & 0.516 & 6 \\
\hline ALT8 & 0.53 & 0.68 & 0.40 & 0.44 & 0.43 & 1.00 & 0.33 & 0.46 & 0.33 & 0.33 & 0.422 & 10 \\
\hline ALT9 & 0.60 & 1.00 & 0.50 & 0.33 & 1.00 & 1.00 & 1.00 & 0.41 & 1.00 & 0.50 & 0.629 & 3 \\
\hline ALT10 & 0.62 & 0.95 & 0.67 & 0.44 & 0.60 & 0.50 & 1.00 & 0.52 & 1.00 & 1.00 & 0.631 & 2 \\
\hline
\end{tabular}

\section{Conclusions}

Adecision-making support model for real estate purchasing was developed in the present study, which included both qualitative and quantitative criteria. The proposed model was constructed using both the DEMATEL and GRA methods, and the link with the criteria provides a higher degree of objectivity in real estate decisions when compared to models that only use experts' judgments. With the proposed model, stakeholders can evaluate real estate alternatives. From a managerial perspective, our model helps investors, buyers make more informed decisions, with tangible evidence, on the selection of one alternative over another. In addition, it constitutes a tool for property managers to determine the potential of each property in the market.

The practical implications of the study are the identification of the criteria and their weights, and the quality of the input and the application of the decision model. The decision model was implemented by the investors and can be applied to other cases of real estate investments. Moreover, the model can also be used in other real estate markets (e.g. commercial, office, or retail development) with little or no modifications. This research also has some implications for the academic community.

\section{References}

Aldalou, E., \& Perçin, S. (2020). Fuzzy MCDM approach in Financial Performance Evaluation of Food and Beverage Index. Uluslararası Ekonomi ve Yenilik Dergisi, (March), 1-19. https://doi.org/10.20979/ueyd.650422

Apergis, N., Hayat, T., \& Kadasah, N. A. (2019). Subjective well-being in housing purchasing: Evidence with survey data from the U.K. housing residential market. Quarterly Review of Economics and Finance, 74, 328-335. https://doi. org/10.1016/j.qref.2019.01.004
Bouchouicha, R., \& Ftiti, Z. (2012). Real estate markets and the macroeconomy: A dynamic coherence framework. Economic Modelling, 29(5), 1820-1829.

Brauers, W. K. M., \& Zavadskas, E. K. (2006). The MOORA method and its application to privatization in a transition economy. Control and Cybernetics, 35(2), 445-469.

Brzezicka, J., Laszek, J., \& Olszewski, K. (2019). An Analysis of the Relationships between Domestic Real Estate Markets: A Systemic Approach. Real Estate Management and Valuation, 27(1), 79-91. https://doi.org/10.2478/remav-2019-0008

Deng J. (1989). Introduction to grey system. Journal of Grey System, 1(1), 1-24.

Fasanghari, M., \& Montazer, G.A. (2010). Design and implementation of fuzzy expert system for Tehran Stock Exchange portfolio recommendation. Expert Systems with Applications, 37(9), 6138-6147. https://doi.org/10.1016/j.eswa.2010.02.114

Gabus, A., \& Fontela, E. (1972). World problems, an invitation to further thought within the framework of DEMATEL. Battelle Geneva Research Center, Geneva, Switzerland.

Geipele, I., \& Kauškale, L. (2013). The influence of real estate market cycle on the development in Latvia. Procedia Engineering, 57, 327-333. https://doi.org/10.1016/j.proeng.2013.04.044

Giannakis, M., Dubey, R., Vlachos, I., \& Ju, Y. (2020). Supplier sustainability performance evaluation using the analytic network process. Journal of Cleaner Production, 247, 119439. https://doi.org/10.1016/j.jclepro.2019.119439

Hott, C. (2011). Lending behavior and real estate prices. Journal of Banking and Finance, 35(9), 2429-2442. https://doi. org/10.1016/j.jbankfin.2011.02.001

Ishtiaq, N., \& Siddiqui, D. A. (2019). Factors Affecting Financial Performance of Life Insurance Sector in Pakistan. SSRN Electronic Journal. https://doi.org/10.2139/ssrn.3400728

Stojanova, B. D., Jovanovic, B., Vojnovic, M. K., Ramadani, G., \& Petrovska, M. (2008). Real estate prices in the Republic of Macedonia (No. 2008-03]). Working Paper. 
Jung, S., Huynh, D., \& Rowe, P. G. (2013). The pattern of foreign property investment in Vietnam: The apartment market in Ho Chi Minh City. Habitat International, 39, 105-113.

Kibunyi, D., Ndiritu, S., Carcel, H., \& Gil-Alana, L. A. (2017). Real estate prices in Kenya: Is there a bubble? Journal of Housing and the Built Environment, 32(4), 787-804. https:// doi.org/10.1007/s10901-017-9541-x

Miller, N., Peng, L., \& Sklarz, M. (2011). House prices and economic growth. The Journal of Real Estate Finance and Economics, 42(4), 522-541.

Nguyen, M. L. T., Bui, T. N., \& Nguyen, T. Q. (2019). Relationships between real estate markets and economic growth in Vietnam. Journal of Asian Finance, Economics and Business, 6(1), 121128. https://doi.org/10.13106/jafeb.2019.vol6.no1.121

Nguyen, P. H., Tsai, J., Kumar G., V. A., \& Hu, Y. (2020). Stock Investment of Agriculture Companies in the Vietnam Stock Exchange Market: An AHP Integrated with GRA-TOPSISMOORA Approaches. Journal of Asian Finance, Economics and Business, 7(7), 113-121. https://doi.org/10.13106/ jafeb.2020.vol7.no7.113

Nguyen, P. T., Le, Q., Thuy, H., \& Nguyen, T. (2020). Critical Factors Affecting Construction Price Index: An Integrated Fuzzy Logic and Analytical Hierarchy Process. Journal of Asian Finance, Economics and Business, 7(8), 197-204. https://doi.org/10.13106/jafeb.2020.vol7.no8.197

$\mathrm{Si}$, P. T. (2012). Key factors affecting house purchase decision of customers in Vietnam. Unpublished master thesis). University of Economics Ho Chi Minh City, Ho Chi Minh City, Vietnam.
Singhal, D., Tripathy, S., \& Kumar Jena, S. (2018). DEMATEL approach for analyzing the critical factors in remanufacturing process. Materials Today: Proceedings, 5(9), 18568-18573. https://doi.org/10.1016/j.matpr.2018.06.200

Škrinjarić, T. (2020). Dynamic portfolio optimization based on grey relational analysis approach. Expert Systems with Applications, 147. https://doi.org/10.1016/j.eswa.2020.113207

TANG, Q., \& JIN, P. (2020). Analysis of Influential Factors of Housing Price in Nanjing Based on Improved Grey Relational Analysis. DEStech Transactions on Social Science, Education and Human Science, 32-36. https://doi.org/10.12783/dtssehs/ mess2019/33721

Wang, S., Yang, Z., \& Liu, H. (2011). Impact of urban economic openness on real estate prices: Evidence from thirty-five cities in China. China Economic Review, 22(1), 42-54. https://doi. org/10.1016/j.chieco.2010.08.007

Yalcin, N., Bayrakdaroglu, A., \& Kahraman, C. (2012). Application of fuzzy multi-criteria decision making methods for financial performance evaluation of Turkish manufacturing industries. Expert Systems with Applications, 39(1), 350-364. https://doi. org/10.1016/j.eswa.2011.07.024

Ying-Yu, W., \& De-Jian, Y. (2011). Extended VIKOR for multicriteria decision making problems under intuitionistic environment. International Conference on Management Science and Engineering - Annual Conference Proceedings, 118-122. https://doi.org/10.1109/ICMSE.2011.6069952

Zhang, X. (2015). Green real estate development in China: State of art and prospect agenda: Areview. Renewable and Sustainable Energy Reviews, 47, 1-13. https://doi.org/10.1016/j.rser.2015.03.012 